NAMI-1009

CROSS-VALIDATION OF A BRIEF VESTIBULAR DISORIENTATION

TEST ADMINISTERED BY A VARIETY OF PERSONNEL

Rosalie K. Ambler and Fred E. Guedry, Jr.
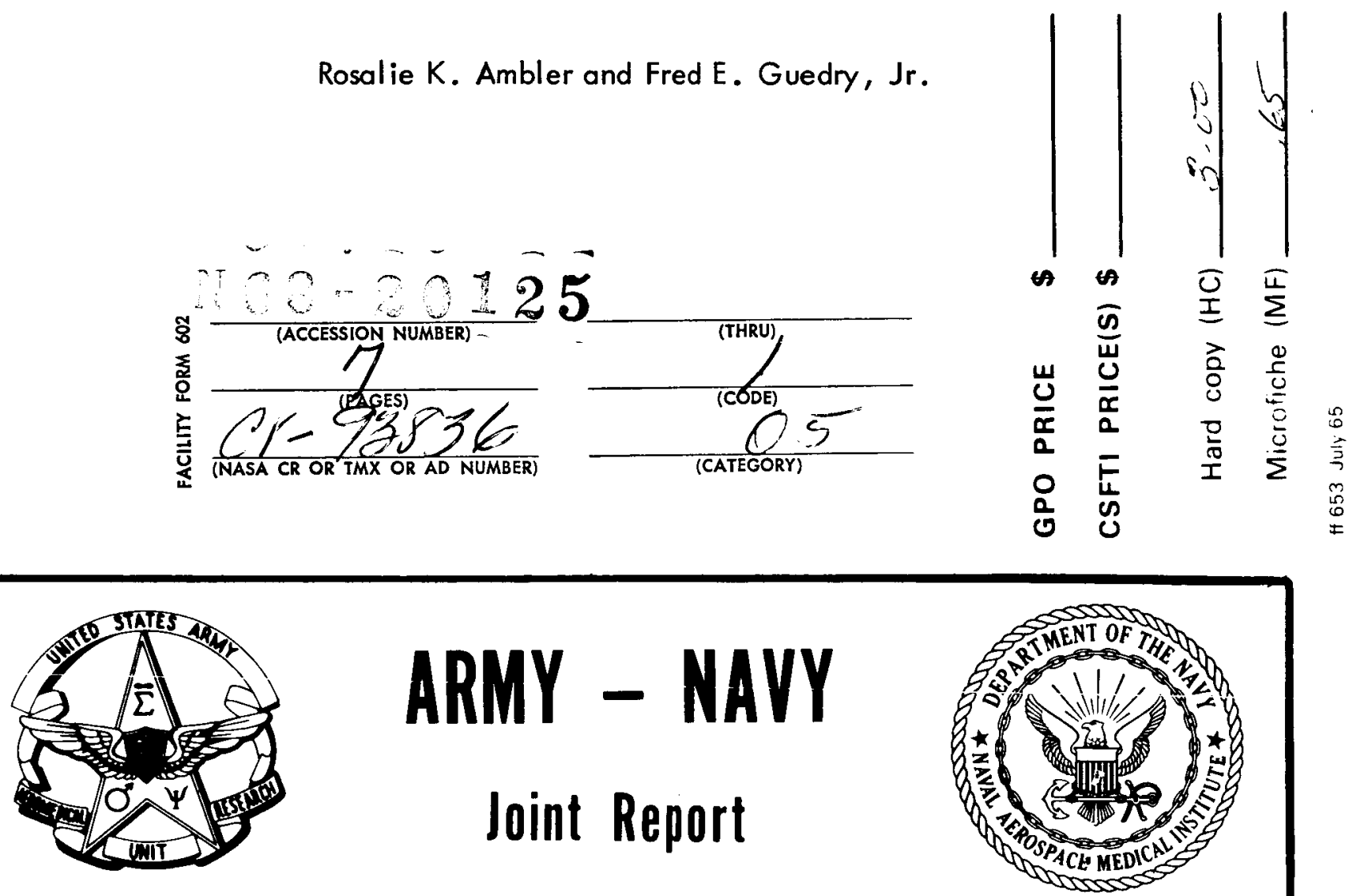

U. S. ARMY AEROMEDICAL RESEARCH UNIT

NAVAL AEROSPACE MEDICAL INSTITUTE

24 May 1967

This document has been approved for public release and sale; its distribution is unlimited.

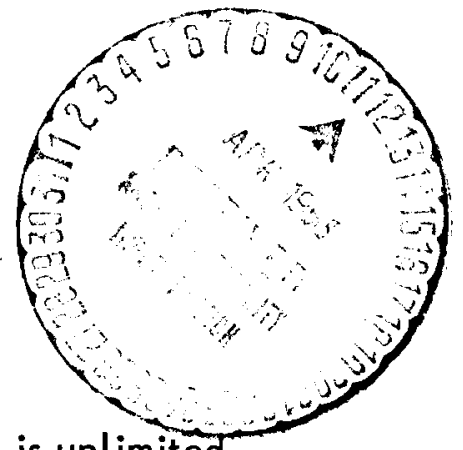


This document has been approved for public release and sale; its distribution is unlimited.

\section{CROSS-VALIDATION OF A BRIEF VESTIBULAR DISORIENTATION TEST ADMINISTERED BY A VARIETY OF PERSONNEL *}

Rosalie K. Ambler and Fred E. Guedry, Jr.

Bureau of Medicine and Surgery

MR005.04-0086. 2

U. S. Army Aeromedical Research Unit

NASA Order R-93

Approved by

Ashton Graybiel, M. D.

Director of Research
Released by

Captain J. W. Weaver, MC, USN Commanding Officer

24 May 1967

*This research was conducted under the sponsorship of the Office of Advanced Research and Technology, National Aeronautics and Space Administration. 


\section{SUMMARY PAGE}

\section{THE PROBLEM}

A Brief Vestibular Disorientation Test (BVDT) has been developed that involves observer assessment of subjects' reactions produced by head movements in a rotat ing chair. Promising val idity coefficients have been reported for a criterion of pass versus separation from pilot training. The purpose of this study was to cross-validate the BVDT under observer conditions approximating field use.

\section{FINDINGS}

Cross-validation was considered successful because significant relationships were found between sensitivity scores on the BVDT and four dichotomous criteria:

1. Students separated from flight training for all causes versus completed.

2. Tension separations versus all other students.

3. Airsick separations versus all other students.

4. Tension and/or airsick separations versus all other students.

High sensitivity scores on the BVDT were related to membership in all four separation groups. The addition of the BVDT significantly augmented the magnitude of the multiple correlations of the existing selection variables with the criterion.

\section{ACKNOWLEDGMENTS}

The investigators would like to acknowledge with gratitude the following individuals who served as raters: Lt. Patrick M. Curran, MSC, USNR, Mrs. Linda M. Crush, Dr. Alfred R. Fregly, Ens. John Hill, MC, USNR, Lt. Charles W. Hutchins, MSC, USN, Lt. Norman E. Lane, MSC, USN, Mrs. Barbara Mart in, Mrs. Judy L. Miller, Mr. Joel W. Norman, Lt. Richard S. Pomarolli, MSC, USNR, HM2 James L. Roberts, USNR, and Mr. Theron L. Trimble. 


\section{INTRODUCTION}

The Coriol is vestibular reaction, which can be el icited by tilting the head during simple whole-body rotation, has been of interest to aviation examiners since the time of World War I. Early attention centered mainly around identifying and describing the phenomenon. More recently, efforts have been made to assess the total behavior associated with the Coriol is vestibular reaction and to correlate these assessments with some external criterion (1-6). Evaluations of individuals experiencing th is Coriol is vestibular reaction have been compared with their subsequent performance in flight training in the Netherlands (5) and Canadian (6) Air Training Commands. Results were encouraging in that the evaluations appeared to predict success and also occurrence of motion sickness in flight training. Performance in a rotating environment also has been found to be predictive of susceptibility to airsickness and seasickness (4).

At Pensacola a Brief Vestibular Disorientation Test (BVDT) has been developed that involves an assessment of subjects' reactions produced by head movements in a rotating chair. A structured rating procedure was introduced to permit brief and objective administration of the test by personnel who have only a modicum of training for the task. Reliability of measurement has been demonstrated by substantial agreement among several types of observers using the BVDT technique for the same subjects and by substantial agreement of the observers' BVDT ratings with the subjects' self-ratings of sensitivity. These data have been reported previously (3). Promising validity coefficients also have been reported for an over-all criterion of pass versus separation from naval pilot training and for a specific criterion of separation for airsickness (1). The purpose of this study was to cross-validate the BVDT under observer conditions approximating field use.

\section{PROCEDURE}

The test was administered to 239 naval pilot trainees during the twelfth week of the 16-week pre-flight syllabus. With the rotatory Stille-Werner chair stationary, each subject was asked to practice slow head movements of 45 degrees with his eyes closed and without mechanical aids. After instructions, the chair was accelerated at $15 \mathrm{deg} /$ $\sec ^{2}$ to a constant velocity of $90 \mathrm{deg} / \mathrm{sec}(15 \mathrm{rpm})$. After 30 seconds the following positions were assumed: head right, upright, left, upright, right, upright, left, upright, forward, upright. Each position was maintained for 30 seconds. The chair was stopped by a $15-\mathrm{deg} / \mathrm{sec}^{2}$ deceleration upon completion of this sequence. The subject was instructed to open his eyes after the sensation of movement stopped. Observers made independent ratings of each subject during the sequence. Rater estimates of pallor, sweating, facial expression, unsteadiness, speed of recovery, and over-all performance were recorded on a ten-point scale. The low point on the scale represented low sensitivity, or no effect. An individual rater's score was obtained simply by summing his judgments on the six factors. The BVDT score for a given subject was the mean of these individual ratings. Raters were told not to make relative judgments of subjects but to judge each man separately. For example, a rating of 10 on sweating would mean that the man was sweating as profusely as possible. The number of observers per subject varied from two to four, with a mode of three. A total of 13 observers with 
The means and standard deviations for the various criterion categories are presented in Table II to demonstrate the magnitude of the differences among these criterion groups.

\section{Table II}

BVDT Score Descriptive Statistics for Various Criteria

Criterion Groups

First Study

Cross-validation

\begin{tabular}{|c|c|c|c|}
\hline Completions & $\begin{array}{l}\bar{X} \\
N\end{array}$ & $\begin{array}{r}12.09 \\
4.67 \\
168\end{array}$ & $\begin{array}{r}13.66 \\
5.68 \\
170\end{array}$ \\
\hline $\begin{array}{l}\text { Separations } \\
\text { (all causes) }\end{array}$ & $\begin{array}{l}\bar{x} \\
\sigma_{N}\end{array}$ & $\begin{array}{r}14.09 \\
7.92 \\
58\end{array}$ & $\begin{array}{r}15.91 \\
8.00 \\
69\end{array}$ \\
\hline Tense separations & $\begin{array}{l}\bar{X} \\
\sigma \\
N\end{array}$ & $\begin{array}{r}14.12 \\
5.40 \\
22\end{array}$ & $\begin{array}{r}19.22 \\
8.48 \\
25\end{array}$ \\
\hline Airsick separations & $\begin{array}{l}\bar{X} \\
N \\
N\end{array}$ & $\begin{array}{r}23.11 \\
13.68 \\
10\end{array}$ & $\begin{array}{r}20.12 \\
7.21 \\
9\end{array}$ \\
\hline $\begin{array}{l}\text { Tense and/or } \\
\text { airsick separations }\end{array}$ & $\begin{array}{l}\bar{X} \\
\sigma\end{array}$ & $\begin{array}{r}16.81 \\
10.14 \\
27\end{array}$ & $\begin{array}{r}18.91 \\
8.47 \\
26\end{array}$ \\
\hline Total & $\begin{array}{l}\bar{X} \\
\mathcal{N}\end{array}$ & $\begin{array}{r}12.64 \\
5.76 \\
226\end{array}$ & $\begin{array}{r}14.23 \\
6.46 \\
239\end{array}$ \\
\hline
\end{tabular}

The significant coefficients for two successive samples suggest that the BVDT is a useful selection instrument. It was necessary, however, to determine whether it augmented existing selection procedures. Research at the Naval Aerospace Medical Institute has developed multiple regression equations for predicting subsequent separation from flight training $(7)$. Separate equations are available for various critical points in training; the predictor variables entering into these equations are drawn from the aviation selection tests and all performance data available up to that given point in training. 
study samples there were no students with FAR scores of 3 and only eight with scores of 4 . The data for both samples are combined in Table IV. Although the number of cases involved is small, the data in Table IV support the inference that extreme reactors on the BVDT (42 or above) cannot complete flight training. Furthermore, there appears to be a significant interaction between the BVDT score and the FAR score in the upper score ranges of the BVDT (15 to 42.9). Students who had BVDT scores in this range and who scored 4 or 5 on the FAR had an attrition rate of 50 per cent while those with a FAR of 6 or above had a somewhat lower separation rate of 32.5 per cent.

\section{Table IV}

Separation Rates for Various BVDT Score Levels and Flight Aptitude Ratings

\begin{tabular}{lrrrr}
$\begin{array}{l}\text { BVDT } \\
\text { Scores }\end{array}$ & \multicolumn{2}{c}{ FAR 4 or 5 } & \multicolumn{2}{c}{ FAR 6 to 9 } \\
Input & \% Separating & Input & Separating \\
\hline $6.0-8.9$ & 17 & 17.6 & 51 & 19.6 \\
$9.0-14.9$ & 69 & 24.6 & 208 & 22.1 \\
$15.0-42.9$ & 36 & 50.0 & 80 & 32.5 \\
$43.0-$ or above & 1 & 100.00 & 3 & 100.0 \\
Total & 123 & 31.7 & 342 & 24.9
\end{tabular}

\section{RECOMMENDATIONS}

It has been demonstrated that this relatively simple method of assessing the Coriol is vestibular reaction in human subjects has significant implications for aviation personnel selection. The evidence supports the recommendation that the BVDT procedure be incorporated into flight student selection. Consideration should be given to the exclusion of all applicants who score 5 or below on the FAR and who also have BVDT scores in the upper ranges. This recommendation is not meant to imply that this avenue of research has ended. Increased reliability, validity, and objectivity in assessing the Coriol is vest ibular reaction are the next goals. 
Unclassified

Security Classification

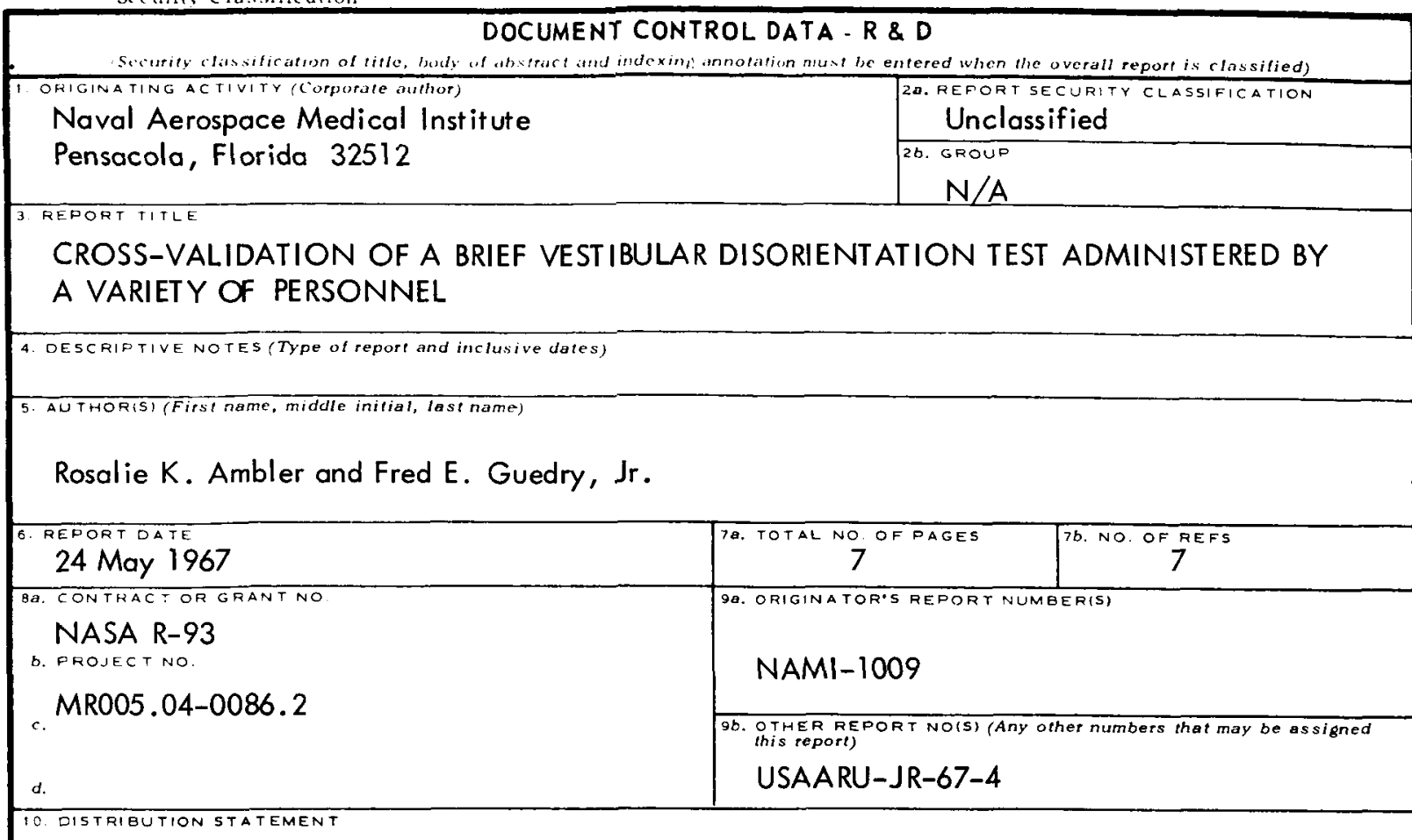

This document has been approved for public release and sale; its distribution is unlimited.

\begin{tabular}{l|l}
\hline 11. SUPPLEMENTARY NOTES & 12. SPONSORING MILITARY ACTIVITY
\end{tabular}

Joint report with U. S. Army Aeromedical

Research Unit, Fort Rucker, Alabama

13. ABSTRACT

A Brief Vestibular Disorientation Test (BVDT) was developed that involves observer assessment of subjects' reactions produced by head movements in a rotating chair. Promising validity coefficients have been reported for a criterion of pass versus separation from pilat training. This study cross-validated the BVDT under observer conditions approximating field use. The test was adm in istered to 239 aviation trainees during pre-flight training. The number of observers per subject varied from two to four. Thirteen observers with a variety of backgrounds participated. BVDT scores were correlated with four criteria: 1) students separated from training for all causes versus completions, 2) tension separations versus all others, 3) airsick separations versus all others, 4) tension and/or airsick separations versus all others. Significant relationships existed between high sensitivity scores on the BVDT and membership in all four separation groups. The addition of the BVDT significantly augmented the magnitude of the multiple correlations of the existing aviation selection variables with the criteria. 